\title{
지속가능발전을 위한 \\ 새로운 역량개발의 전략모색
}

\section{목 차}

I. 들어가며

II. 지속가능발전목표와 역량개발

1. 개발목표의 이행수단으로서의 역량개발

2. 아디스아바바 행동계획과 역량개발

III. 개발을 위한 역량개발의 다양한 접근법

1. 역량개발의 개념

2. 역량개발의 다양한 접근법

IV. 결론: 새로운 역량개발 전략을 위한 시사점

\section{I. 들어가며}

지속가능발전목표(Sustainable Development Goals, 이하 SDGs)에 대한 논의로 뜨거운 한 해 다. 지난 2015년 7월 에티오피아 아디스아바바에서는 이 방대하고 야심찬 지속가능발전목표의 실현 을 위한 재원에 대해 논의하는 제 3차 개발재원총회(International Conference on Financing for Development)가 개최되었다. 제 70회 유엔총회(70th session of the General Assembly) 직전에 개최된 이번 아디스아바바 개발재원 회의는 전 세계적으로 뜨거운 관심을 받았다. ${ }^{1)}$ 공적개발원조의

1) 제 3 차 개발재원총회와 아디스아바바 행동계획에 관한 상세한 내용은 아래 보고서를 참고하기 바람. 박수영 - 오수 현. 2015, '제3차 개발재원총회와 아디스아바바 행동계획의 함의 분석 연구.' ‘개발과 이슈! 24호(2015년 8월호). 성 남: 한국국제협력단 
규 모가 전 세계적으로 축소될 것이 예상되는 가운데 새로운 개발재원을 모색하자는 논의의 장이 많 은 관심을 받은 것은 자연스러운 현상일 것이다. 그럼에도 불구하고 혁신적인 개발을 위한 국제사회 의 자원(resources)에 대한 논의가 지나치게 재원(financial resources)으로만 한정되는 것은 유의 할 필요가 있다. 개발재원에 관한 논의와 함께 민관협력, 과학기술혁신, 역량강화, 새로운 글로벌파트너 십과 같은 새로운 메커니즘으로서 특히, 새로운 개발목표 달성을 위한 핵심 요소로서 역량개발에 대 한 논의도 지속되어야 할 것이다.

Post-2015 개발의제에 관한 유엔사무총장 종합보고서(Road to Dignity by 2030: ending poverty, transforming all lives and protecting the planet, 이하 유엔사무총장 종합보고서 ${ }^{2)}$ ) 및 각종 결과문서에서는 새로운 개발목표를 달성하는 데에 필수 불가결한 요소로서 역량강화를 언급하 고 있다. ${ }^{3)}$ 본고에서는 최근 논의되고 있는 개발의 혁신적인 메커니즘 중 역량개발에 대한 개념과 다 양한 접근법을 소개하고 나아가 지속가능발전 시대에 우리나라 공적개발원조 사업 전략에 주는 시 사점을 모색하고자 한다. 이와 같은 맥락에서 첫째, 지속가능발전이라는 커다란 틀에서 개발의 중요 한 자원으로서 역량(capacity)이라는 개념에 대해 알아보고, 둘째, 혁신적이고 지속가능한 발전을 이 루어내기 위한 수단이자 지속가능발전의 중요한 목표 그 자체로서 역량개발에 대한 다양한 접근법 (approaches to capacity building or development)을 정리하며, 셋째, 역량개발이 우리나라 ODA 전략과 사업에 주는 함의를 제시하고자 한다.

\section{III. 지속가능발전목표와 역량개발}

\section{1. 개발목표의 이행수단으로서의 역량 개발}

Post-2015 개발의제에 관한 주요 정책 논의에서 제도적 역량강화와 인적 역량강화는 Post-2015 개발목표 실현을 위한 핵심 이행수단(means of implementation, MoI)으로서 간주되어지고 있다(< 박스 1> 참고). 유엔사무총장 종합보고서에서는 지속가능한 발전을 위해 다양한 유형과 형태의 역량 개발에 투자해야함을 언급하면서 무려 여섯 조항에 걸쳐 역량강화의 중요성을 강조하고 있다. 그 주 요 내용은 아래와 같다.

2) Post-2015 의제에 관한 UN 사무총장 종합보고서 분석에 대한 국문 분석은 아래 보고서를 참고하기 바람. 김지현. 2015, 'Post-2015 개발의제 동향연구 2 : Post-2015 의제에 관한 UN 사무총장 종합보고서 분석.' '개발과 이슈」: 22호 (2015년 1월호). 성남: 한국국제협력단

3) 상세한 내용은 아래 UN 문건을 참고하기 바람. Road to Dignity by 2030: ending poverty, transforming all lives and protecting the planet (2015) 
첫째, SDGs을 달성하기 위한 국가기관의 제도 역량의 강화가 시급하다. 국가 정책 기획, 예산, 법 제 및 제도 개선 절차에 SDGs를 연계해야하는 작업이 중요한데, 이를 위해서는 효과적이면서도 역량 과 기술을 겸비한 인력을 보유한 기관의 역량이 중요하기 때문이다. 정부는 다양한 이해관계자와 함 께 국가정책 우선순위에 근거하여 목표를 달성하기 위한 국가예산과 정책을 검토하는 과정을 진행해 야 한다(127항). 특히, SDGs를 집행하는 기관, 국회, 사법 기관도 SDGs를 현실화하는데 필요한 정책 역량이 필요할 것이다(129항). 특별히 국제사회가 개발도상국가들의 역량강화를 위한 지원을 더욱 강 화해야하는데 최빈국과 분쟁 후 국가들이 경우, 이들 국가와 인력의 역량강화를 위한 지원이 상당히 절실하다(130항).

둘째, 실제 지역수준의 사업을 기획, 이행, 모니터링 할 수 있는 지방자치단체의 리더십과 역량강 화이다. 지속가능발전정책은 지방자치단체 스스로 정책을 검토하고 이행하는 과정 자체를 주도해야 만 실현이 가능한 것이다. SDGs 이행과 모니터링을 위해서는 지역수준의 인적 역량이 강화되어야 한 다. 사업기획 단계에서 지역 욕구와 수요를 조사하고, 데이터를 수집하며, 다양한 섹터와 기관의 의견 을 구조화할 수 있도록 지역 수준의 역량이 더욱 강화되어야 한다(128항).

셋째, 시민의 참여 확대와 시민사회 및 봉사자들의 역량강화가 강조되어야 한다. 시민사회의 경우 비판적이고 독립적인 역할을 위한 역량이 중요할 것이며(129항), 시민과 자원봉사자의 경우 이들의 자발적인 국가정책 참여와 지역수준의 사업에 참여하고 모니터링 하는데 역량이 강화되는 것이 중요 하다고 강조하고 있다. 유엔은 자원봉사가 지속가능한 사회를 만드는 데 강력한 개발의 이행 수단임 을 인지하고 있으며, 자원봉사는 지속가능한 발전을 위한 국가 계획의 수립과 이행과정에서 핵심적인 사람들을 동원하고 참여하도록 하는 데 큰 역할을 할 수 있다며 자원봉사의 중요성을 언급하였다(131 항). 이와 같은 맥락에서 새로운 변혁의 아젠다를 실현하기 위한 지속가능발전에 대한 이해를 제고하 는 것이 필요하고 이러한 노력은 정부와 정부기관들만의 영역으로만 남아서는 안 된다고 분명히 명시 하고 있다. Post-2015 개발의제를 변혁의 아젠다(transformative agenda)라고 칭하는데 이와 같은 사회변화를 실현하기 위해서는 문화의 힘을 간과해서는 안 될 것이다. 문화는 변화를 만드는 가장 강 력한 힘을 가지고 있으며 SDGs를 내재화하고 실현화하기 위한 강력한 힘을 내재하고 있다고 강조하 고 있다(132항).

Post-2015 개발의제에 관한 결과문서(Zero Draft of the Outcome Document for the UN Summit to adopt the Post-2015 Development Agenda, 이하 결과문서 $)^{4}$ 에서도 역량강화에 대한 내용을 찾아볼 수 있다〈박스 2〉 참고. Post-2015 개발의제의 이행을 강화하기 위해 국제사회는 효과

4) 상세한 내용은 아래 UN 문건을 참고하기 바람. Zero Draft of the Outcome Document for the UN Summit to adpot the Post-2015 Development Agenda (2015) 


\section{유엔 사무총장 보고서 주요 내용 \\ Mobilizing the means to implement our agenda \\ C. Investing in capacities for sustainable development}

127. To achieve our goals, countries need to integrate them into national planning, policy, budgets, law and institutions. They will require integrated institutions that are effective, and human resources equipped with the skills and capacities to deliver sustainable development. Governments, in consultation with all stakeholders, and, consistent with national priorities, will need to review national strategies and policies to support progress towards the goals.

128. These strategies will also have to be reviewed and implemented at the local level, with the full engagement of local authorities. In many instances, subnational and local authorities, including mayors, are already leading the charge for sustainable development. Institutional and human capacities will, in many cases, need to be strengthened for effective implementation and monitoring. This includes bolstering capacities to assess needs, collect data and formulate responses across sectors a nd institutions.

129. Executive institutions, parliaments and the judiciary will need the capacity to perform their functions in this endeavor. In addition, institutions of civil society must have the capacity to carry out their critical, independent roles.

130. Developing countries will need support for capacity-building. The least developed countries and post-conflict countries will have particularly urgent needs. For this, the United Nations is working to revitalize and improve its role in capacity development. Here too, ambition will need to be scaled up, especially in the immediate term, not only by the United Nations, but by all partners in the process. See quadrennial comprehensive policy review of operational activities for development of the United Nations system (see, most recently, A/67/93-E/2012/79).

131. As we seek to build capacities and to help the new agenda to take root, volunteerism can be another powerful and cross-cutting means of implementation. Volunteerism can help to expand and mobilize constituencies and to engage people in national planning and implementation for sustainable development goals. And volunteer groups can help to localize the new agenda by providing new areas of interaction between Governments and people for concrete and scalable actions.

132. Finally, we must also mobilize the power of culture in the transformative change we seek. Our world is a remarkable mosaic of diverse cultures, informing our evolving understanding of sustainable development. We still have much to learn from global cultures as we build the world we want. If we are to succeed, the new agenda cannot remain the exclusive domain of institutions and Governments. It must be embraced by people. Culture, in different aspects, will thus be an important force in supporting the new agenda.

* 출처: Road to Dignity by 2030: ending poverty, transforming all lives and protecting the planet (2015) 
〈박스 2〉

\section{OWG 결과문서의 주요 내용}

17.9. Capacity-building: Enhance international support for implementing effective and targeted capacity-building in developing countries to support plans to implement all sustainable development goals, including through North-South, South-South and triangular cooperation.

* 출처: Zero Draft of the Outcome Document for the UN Summit to adpot the Post-2015 Development Agenda (2015)

적이고 집중된 개발도상국의 역량강화에 기여해야한다. SDGs를 이행하는 역량뿐 아니라 북-남 협력, 남-남 협력 그리고 삼각협력 등을 지원해야 한다는 것이다(17.9항). 이와 같이 Post-2015 개발의제에 관한 결과문서에도 제도적 역량강화와 인적 역량강화를 개발목표 달성을 위한 중요한 이행수단의 두 축으로 강조하고 잇는 것을 확인할 수 있다.

\section{2. 아디스아바바 행동계획과 역량개발}

앞서 설명한 바와 같이, 이번 3차 개발재원총회에서는 개발도상국의 빈곤퇴치와, 경제 - 사회 환경 개발을 위해 동원 가능한 재원이 무엇이며, 이러한 재원의 조달 및 활용을 위해서는 어떠한 수단이 필요한지에 대한 논의가 진행되었다. 개발재원(Development Finance)을 "포괄적으로 개 발도상국의 빈곤퇴치와 지속 가능한 경제·사회 발전을 위해 필요한 재원”으로 정의(박수영 · 오 수현, 2015) 할 때, 이러한 재원이 효과적이고 임팩트있게 활용되기 위한 이행의 수단(means of implementation)으로서의 제도적 역량, 개인의 역량, 기술, 전문성, 지식 등에 대한 논의가 병행되 는 것이 중요할 것이다.

이번 개발재원총회에서는 총 134항으로 구성된 아디스아바바 행동계획(Addis Ababa Action Agenda, 이하 아디스아바바 행동계획)을 채택하였는데, 본 행동계획은 Post-2015 개발재원을 위한 글로벌 프레임워크, 7 대 분야별 행동분야 및 데이터 및 모니터링에 관한 내용을 담고 있다. 이번 행동 계획에서도 Post-2015 개발 의제를 달성하는 데에 필수 불가결한 요소로서 역량강화를 강조하고 있 는 것을 발견 할 수 있다. 역량강화에 대한 내용은 아디스아바바 행동계획 7대 행동분야 중에서도 "과 학, 기술, 역량강화(science, technology, innovation and capacity-building)”ㄷ)으로 함께 언급되 어 있는 것은 반가운 일이다〈박스 3 〉.

5) 상세한 내용은 아래 UN 문건을 참고하기 바람. Addis Ababa Action Agenda of the Third International Conference on Financing for Development (Addis Ababa Action Agenda) (2015) 


\section{〈박스 3〉}

\section{아디스아바바 행동계획 중 115항, 118항, 119항의 주요 내용}

\section{G. Science, technology, innovation and capacity-building (114 124)}

115. Capacity development will be integral to achieving the post-2015 development agenda. We call for enhanced international support and establishment of multi-stakeholder partnerships for implementing effective and targeted capacitybuilding in developing countries, including least developed countries, landlocked developing countries, small island developing States, African countries, and countries in conflict and post-conflict situations, to support national plans to implement all the sustainable development goals. Capacity development must be country-driven, address the specific needs and conditions of countries and reflect national sustainable development strategies and priorities. We reiterate the importance of strengthening institutional capacity and human resource development. It is also critical to reinforce national efforts in capacity-building in developing countries in such areas as public finance and administration, social and gender responsive budgeting, mortgage finance, financial regulation and supervision, agriculture productivity, fisheries, debt management, climate services, including planning and management for both adaptation and mitigation purposes, and water and sanitation related activities and programmes.

118. We also recognize the important role of public finance and policies in research and technological development. We will consider using public funding to enable critical projects to remain in the public domain, and strive for open access to research for publicly funded projects, as appropriate. We will consider setting up innovation funds where appropriate, on an open, competitive basis to support innovative enterprises, particularly during research, development and demonstration phases. We recognize the value of a "portfolio approach" in which public and private venture funds invest in diverse sets of projects to diversify risks and capture the upside of successful enterprises.

119. We resolve to adopt science, technology and innovation strategies as integral elements of our national sustainable development strategies to help to strengthen knowledge-sharing and collaboration. We will scale up investment in science, technology, engineering and mathematics education, and enhance technical, vocational and tertiary education and training, ensuring equal access for women and girls and encouraging their participation therein. We will increase the number of scholarships available to students in developing countries to enrol in higher education. We will enhance cooperation to strengthen tertiary education systems, and aim to increase access to online education in areas related to sustainable development.

* 출처: Addis Ababa Action Agenda of the Third International Conference on Financing for Development (Addis Ababa Action Agenda) (2015) 
지속발전목표와 관련된 주요 보고서에서도 다뤄진 바와 같이, 이번 아디스아바바 행동계획에서도 Post-2015 개발 의제를 달성하는 데에 필수 불가결한 요소로서 역량개발을 강조하고 있다. 행동계획 115 항에서 "개발도상국, 소규모 도서국, 아프리카의 국가들, 분쟁 혹은 분쟁 후 국가들에서의 효과적이 고 집중된 역량강화가 필요하다"고 명시하면서 이와 같은 역량강화를 위한 파트너십 구축과 국제적 지 원의 확대가 중요함을 강조하였다. 무엇보다도 역량강화의 주체가 국가임을 다시 한번 부각하고 있는 것은 주목할 만하다. 다양한 역량강화 사업과 활동은 개별 국가들의 구체적인 수요에 근거하여 기획되 고 제공되며, 국가별로 가장 시급하고 심각한 문제를 해결하는 데 기여한다고 강조하였다. 아디스아바 바 행동계획에서 다루고 있는 국가 스스로 선정한 지속가능발전 정책상의 우선순위에 근거해야 한다는 것이다. 역량강화의 주제와 내용도 중요하다. 특히, 아디스아바바 개발재원 회의에서는 공공재정과 행 정, 금용제도 및 감독 및 부채 관리, 사회보호 예산 편성 및 성인지 예산 편성, 기후변화, 농업 및 어업 그리고 물과 위생관련 사업과 활동에서의 역량강화가 시급하다고 강조하였다.

제I장

\section{III. 개발을 위한 역량개발의 다양한 접근법}

\section{1. 역량개발의 다양한 개념}

혁신적이고 지속가능한 발전을 이루어내기 위한 수단이자 지속가능발전의 중요한 목표 그 자체로 서 역량강화에 대한 강조가 지속적으로 언급되고 있지만, 국제적으로 개발을 위한 역량개발(capacity for development)에 대해 하나의 합의된 정의가 존재하는 것은 아니다(Lusthaus et al., 1999; WorldBank, 2009). ${ }^{6}$ 역량이라는 개념이 도입되고 역량강화와 역량개발에 대한 논의가 개발협력에 주류 논의로 받아들여진 것은 이미 1990년대부터이나 (차은주 외, 2014), 국가마다 '역량개발'에 대한 접근법과 궁극적은 전략목표는 상당히 상이하다. 이는 각각의 원조기관들이 가지고 있는 고유한 원조 사업에 대한 방향, 인식, 문화에 영향을 받아 원조기관 특유의 사업수행체계와 사업형태로 발전된다 (홍문숙 외, 2013). 그럼에도 각 기관의 정의에서 공통적으로 파악되는 사항이 있는데, 그것은 역량개 발이 개인뿐만 아니라 조직과 제도를 포괄해야 하며, 관련된 고유한 문화와 환경을 고려해야 한다는 것이다(Pearson, 2011; OECD, 2006; 임소진, 2013; CGIAR, 2013; 이태주 외, 2015).

6) 해외 양자 및 다자 기관들의 역량강화에 대한 접근법에 대한 동향은 아래 보고서를 참고하기 바람. 차은주 - 성민 경 · 박선경 · 강민지 · 신민경. 2014. “역량개발 동향 및 성과제고 방안” ·국제개발협력」 : 2014년 제1호. 성남: 한국 국제협력단

7) 해외원조기관들의 다양한 정책수립 및 사업형성체계에 대한 상세한 내용은 아래 연구보고서를 참조하기 바람. 홍문 숙 · 유성상 · 이태주 · 김형식 · 오수현. 2013. "타 해외 원조기관 정책 수립 및 사업수행체계연구". 사회개발팀. (사) 글로벌발전연구원(ReDI). 성남: 한국국제협력단 
세계은행은 역량(capacity)과 관련된 정의를 두 가지로 구분하고 있다(이태주 외, 2015). ${ }^{8)}$ 첫째 는 개발을 위한 역량(capacity for development)이고, 둘째는 역량개발(capacity development 또 는 capacity building)이다. "개발을 위한 역량(capacity for development)"은 자원 이용 가능성 (availability), 그리고 지속적으로 개발 목표를 확인하고 추진함에 있어 이러한 자원들을 사용하는 효 과성과 효율성을 의미한다. 전자는 “사회정치적, 정책적, 조직적 변화에 의해 향상”될 수 있고, 이러 한 변화는 사회 여러 층위에서 지식과 정보가 어떻게 적용되는지와 연관되어 있는 개념이다(이태주 외, 2015). 이와 같은 개발을 위한 역량개발은 사회정치적, 정책적, 조직적 요소들의 변화를 가져올 수 있는 리더, 단체 및 변화의 주도자의 학습 과정을 강조하는 접근법을 가지고 있다. 이태주(2015)는 "역량개발 사업은 개발을 둘러싼 제반 환경에 영향을 미칠 수 있는 변화를 이끌 주도자의 학습을 통하 여 개발을 위한 역량을 확보하는 데에 그 목적이 있다고 할 수 있으며 역량개발의 성과 관리 또한 이 러한 목적에 입각하여 이루어져야 한다”(이태주 외, 2015). 후자인 역량개발(capacity development 또는 capacity building)은 지속적으로 개발 목표를 확인하고 추진함에 있어 이러한 자원들을 사용하 는 효과성의 증진과 효율성의 강화의 입장에서 역량을 간주하고 있는데서 그 근본적인 접근법이 상이 하다. 궁극적으로 역량을 자원으로 보고 이를 위한 유용성을 더욱 강조하는 입장이다. 역량개발에 대 한 도구적인 중요성을 꾸준히 강조해 온 것은 세계은행이 대표적인데, 이와 같은 국제기구와 원조기 관들은 자원의 이용 가능성은 단순히 경제적, 기술적 자원만을 의미하는 것이 아니라, 역량적인 자원 도 모두 포함하는 것이라고 강조하며, 역량개발을 개발 목표 달성을 위한 중요한 필요 조건으로 강조 하고 있다(이태주 외, 2015).

한편 $\mathrm{OECD} / \mathrm{DAC}$ 은 역량개발을 “전체로서의 사람, 조직, 사회가 장기간 동안 역량을 촉발, 강 화, 형성, 적응, 유지하는 과정”이라고 정의한다 $(\mathrm{OECD}, 2006)$. 대부분의 $\mathrm{DAC}$ 회원국이 동 정의를 인정하면서도 국가마다 강조하는 부분에는 다소 차이가 있다. 한국국제협력단(이하 KOICA) 역량개 발부(차은주 외, 2014)에 의하면 영국은 수원국의 상황에 맞게 조정된 역량개발 지원과 제도적 측면 을 강조하며, 독일의 경우, 역량개발에서 우호적인 환경구축과 시민사회 및 민간부문의 역량개발을 강조하고 있다는 조사 결과를 발표했다. 또한 일본의 경우 과거 역량개발의 범위가 기술협력에 한 정되어 정책, 제도의 영역과 민간부문 역량개발은 지원하지 않았으나, 최근에는 수원국의 개인, 조 직, 제도로 지원의 범위를 넓히고 있다고 보고하였다. 이와 같이 해외공여국과 공여기관들은 역량강 화와 역량개발이라는 개념을 국제개발협력의 중요한 주제로 간주하여 다양한 역량개발 관련 목표를 선정하고 관련 사업을 전략적으로 진행하고 있는 것을 확인할 수 있었다.

8) 이태주 · 홍문숙 · 김헌 · 남종민 · 추빛나. 2015. 연수사업 성과점검 및 성과관리체계 구축연구」. (사)글로벌발전연 구원(ReDI). 성남: 한국국제협력단(발간예정) 


\section{2. 역량개발에 대한 다양한 개념적 접근법}

역량개발에 대한 개념이 1990년대를 기점으로 국제개발에 도입이 되고 개념이 발전되면서 자연스 럽게 역량 그리고 역량개발을 보는 개념적 접근법 또한 다원화되고 있다. 그 중에서도 개발에서의 역 량개발 전략과 사업에 많은 영향을 끼친 접근법은 (i) 비교적 전통적인 접근이라고 볼 수 있는 제도적 접근법(institutional approach), (ii) 조직 차원의 변화를 강조하는 조직개발 접근법(organizational development approach), (iii) 역량강화의 과정 자체와 조직과 개인의 경제·사회·문화적 엠파워먼 트를 강조하는 참여적 접근법(participatory approach), 그리고 (iv) 국내 개발협력에서는 활발히 적 용되지 않고 있지만 향후 개발협력의 사업 기획과 평가에 많은 시사점이 있을 것으로 예상되는 시스 템 접근법(systems perspective)등이 있다. 본 절에서는 현재 개발을 위한 역량에 영향을 주고 있고 적용되고 있는 위와 같은 네 가지 접근법을 소개하고자 한다.

\section{1) 제도적 접근법}

역량개발에 관한 가장 전통적인 접근은 제도적 접근법(institutional approach)이다. 제도적 접근 법 자체가 워낙 방대하고 그 세부분야 또한 다양하지만 일반적으로 기관 혹은 직제에 관한 명확한 기 술을 중심으로 법적인 체계와 제도 자체를 강조하고 있다. Lusthaus et al.(1999, 2002)에 의하면 실제 제도적 접근법이 상당히 방대함에도 불구하고 각종 국제개발협력 관련 보고서에는 다양한 제도 의 유형, 범위, 형식 등을 혼재해서 사용되고 있음을 지적하고 있다. 국내에서도 제도적인 역량강화 를 지칭할 때, 제도(institution)와 기관(organization)을 구분하지 않으며 제도적 접근법이 제도개발 (institutional development) 자체와 혼재되어 사용되고 있는 상황이다.

이러한 다양한 개념이 혼재되어 사용되고 있지만 대부분 개발문제의 근저를 이루는 쟁점들이 법체 계 확립, 행정제도 개선과 같은 한 국가의 제도와 관련된 문제를 다루고 있기 때문에 거시적인 관점에 서 제도적 접근법은 국제개발협력에서의 역량강화에 주는 시사점이 크다. 특히, 대규모 기간사업, 국 가단위의 시스템 구축, 국가단위의 정책 체계 수립 등의 사업과 활동과 연계된 부분에서는 제도적 접 근법의 관점에서 역량개발 전략에 중요한 개념적 틀을 제공할 수 있을 것이다. 지난 $2 \sim 3$ 년간 국제개 발협력계에서는 정책컨설팅 사업의 성과에 대한 논의가 다시 활기를 띄고 있는데, 제도적 접근법을 활용하여 현재 진행되고 있는 우리나라 공적개발원조 정책과 제도 개선 사업과 자문활동의 성과를 점 검하고 전략을 재수립하는 개념적 근간을 제공 할 수 있는 가능성이 있을 것이다. ${ }^{9}$ 우리나라 정책컨설

9) 이태주 · 홍문숙 · 김헌 · 남종민 · 추빛나. 2015. 「연수사업 성과점검 및 성과관리체계 구축연구」. (사)글로벌발전연 구원 (ReDI). 성남: 한국국제협력단(발간예정) 
팅 사업과 활동은 협력국가의 제도 개선에 어떠한 기여를 했으며, 이와 같은 제도 개선 과정과 활동의 성과로서 협력국가에는 어떠한 역량이 개발되었는지 검증이 필요하다. 이와 같이 다양한 유형의 제도 적 접근법이 적용되어 우리나라 $\mathrm{ODA}$ 새로운 정책역량강화 프로그램을 기획하고 평가하는 데 유용한 개념적 근거를 제공할 수 있을 것으로 기대해본다.

\section{2) 조직개발 접근법}

공적개발원조 사업의 효과성을 증진하기 위해서는 개발사업을 기획하고 이행하고 평가하는 전 과 정에서의 조직 자체의 중요성을 간과하지 않을 수 없다. 이와 같은 맥락에서 1990년대부터 영국에서 는 조직개발접근법(organizational development approach)이 다양한 기관과 조직에서 중요한 이론 적 - 개념적 근거를 제공해왔다. Hilderbrand and Grindle(1996)은 조직개발 접근법에서 본 역량개 발을 “공공부문 기관들의 개인 혹은 다른 기관들과의 협업을 통해 업무 능력을 향상시키는 것”이라고 정의하였다. 최근 조직개발접근법을 다양한 영리사업의 기획과 평가에 도입하여 적용해온 William J. Rothwell(2012)에 의하면 조직개발접근법이란 "변화에 영향을 받는 사람들의 참여를 통한 변화 노 력(change effort that is carried out in a participative way, involving those affected by the change)'으로 정의하고 있다. 이와 같이 조직개발접근법은 역량개발의 핵심을 조직 자체와 조직 내의 역동성에 있다고 간주하고 조직 자체를 발전시킴으로써 개발성과를 보다 효과적으로 달성할 수 있다 고 보았다.

조직개발접근법(organizational development approach)은 조직개발의 핵심인 역량을 개발하 는 열쇠가 해당 기관의 구성원, 기관 그리고 기관 내의 다양한 그룹 내에 존재하고 있다고 강조한 다. 조직개발접근법은 기관 자체의 역량강화에 초점을 맞추어 조직의 문제를 해결할 수 있는 실마리 를 제공하는 데 방점을 두고 있다는강점이 부각되면서 2000년대 초반부터 국제개발협력관련 정부기 관, 민간단체 및 지역사회에서 조직의 문제를 개선하고 조직전략을 수립하는데 방대하게 적용되었다 (G.Morgan, 1989). 특히, Folwer와 같은 이들의 노력으로 영국 정부 및 영국 시민사회기관들이 이 와 같은 접근법을 적용하여 조직전략을 구체화하고 조직 역량을 강화하는 접근법으로 활용되었다. 이와 같은 조직개발 접근법은 좀 더 대중적이고 실용적인 조직 역량강화의 근간으로 각광을 받았다 (Lusthaus et al. 1999, 2002).

그러나 조직을 중심에 위치하여 역량개발을 보는 관점은 외부로 표현된 개방적인 이미지는 달리, 방법론적으로는 지나치게 체계 중심적이고, “살아있는 조직을 폐쇄적인 매트릭스에 갇혀 조직화”하려 고 한다는 점에서 기존의 전통적인 접근법과 상이하지 않다는 비판을 받았다(Lusthaus et al., 1999; 2002). 특히, 조직의 체계를 중심으로 역량강화가 이루어지다보니 기관 내부체계 즉 관료 체계를 강 화하는데 집중하였고 조직이 처하고 있는 사회적 가치 및 정치 - 경제적 상황과 같은 외부환경들과 기 
관과의 관계와 같은 중요성이 다소 덜 부각되는 한계도 존재했다. 무엇보다도 개인의 능력과 역량을 강화하여 조직의 결과로 변환하는 시스템이 부족하다는 평, 그리고 각 섹터별 특성을 살린 역량강화 의 논의가 포함되지 못한다는 한계가 발견되었다(Lusthaus et al., 1999; Van Diesen, 1996).

제I장

\section{3) 참여적 접근법}

개발목표 자체보다 개발 목표를 달성하기 위한 과정과 수단의 중요성을 강조하는 참여적 접근법 (participatory approach)가 있다. 앞서 제도적인 접근법과 조직개발접근법이 국가, 체계, 조직에 방 점을 두고 제도적이고 조직적인 역량개발에 중점을 두었다면, 이를 가능하게 하는 개인과 그룹을 어 떻게 움직일 수 있느냐라는 질문에는 많은 의문이 제기되었다. 이러한 의미에서 이미 '제도권 밖'의 인 류학, 여성학, 농촌사회학 등에서 발전된 참여와 엠파워먼트와 같은 개념이 지연스럽게 국제개발의 접근법와 사업에 차용되었다. 사실 참여적 접근법은 다른 접근법들과는 배치되거나 분리된다는 것 보 다는 종종 조직, 제도, 체계적 접근법과 중첩되고 또 동시에 기존의 틀안에 적용이 될 수 있는 접근법 이라고 할 수 있다.

참여적 접근법에서의 역량개발은 국제개발 사업과 활동의 과정에 적용이 되는 핵심 '수단'일 뿐 아 니라 개발 사업과 활동의 궁극적은 목적으로도 간주된다는 점에서 다른 접근법과는 그 철학적 개념적 근간이 차별된다. 근본적으로 참여적 접근법의 핵심적 가치는 변화와 학습이다. 참여적 접근법은 과 정 중심적이고 인간중심적인 철학에 근거하기 때문에 개발의 과정을 통해 일어나는 개인의 변화에 관 심이 둔다는 데 다른 접근법과의 차별성이 있다. 자연스럽게 참여적 접근법은 '개발의 오너십을 누가 가지고 있는가'라는 질문을 강조한다. 국제개발협력 사업에서 개발의 주체를 누구로 규정하는가, 개 발의 과정에서 개발의 주체가 어떻게 어떠한 역할을 가지고 있는가, 개발의 성과는 누구에게 배분되 어져야 하는가, 개발을 위한 참여(participation)와 엠파워먼트(empowerment)를 어떻게 차별화하여 판단 할 것인지, 누가 어떠한 주도권을 가지고 무엇을 위해 '역량을 강화'해야 하는 것인지에 대한 논 의를 심화 발전시키는 것이 중요하다. 개개인의 변화가 매우 중요하지만 그들의 양적 및 질적 변화가 어느 시점에 역량개발에 영향을 주는지 판단하는 것은 단순하지 않은 작업이다. 결론적으로 개인훈련 과 같은 폭 좁은 개발성과를 가진 사업이 역량개발이라는 이름 아래 진행될 수 있지만 이는 개발성과 달성에 어떠한 영향을 미치는지 그 기여를 명확히 하는 데는 한계가 많다는 지적이 있다.

\section{4) 체계이론 접근법}

앞서 제시된 제도적 접근법과 조직개발접근법에서 한 발짝 나아가 체계이론 접근법(systems perspective)을 발견할 수 있다(Lusthaus et al. 1999, 2002). 체계이론 접근법이란, 생물학자인 Ludwig von Bertalanffy, 사회학자인 Talcott Parsons와 조직체계이론 학자인 Peter Senge 등 
의 아이디어에서 발전된 새로운 사회과학의 접근법이다. 1990년대 중반부터 인적자원개발전문가와 Debora Hammond와 같은 교육학자들에 의해 다양한 교육, 연수 및 교육심리 프로그램의 모델에 적용 되어지고 있는 다학제간 체계 접근법으로 국제개발협력에서는 영국과 미국에서 이와 같은 접근법을 접 목시키고 있다(Lusthaus et al. 2002). 체계이론 접근법의 향후 국제개발협력 분야의 제도개선과 개인 의 역량강화의 사이에서 어떠한 형태로 적용이 되어 발전될지 지켜봐야 할 것으로 판단되지만, 접근법 자체가 가지고 있는 역량개발 자체를 다차원적으로 개념화하고 있는 접근법, 조직과 같은 체계가 다양 한 내적 외적 요인들과 서로 연계되어 있다는 점에서 총체적, 다면적, 상호성을 강조하고 있는 점은 분 명히 새로운 역량개발의 담론을 바꿀 수 있는 이론적, 개념적 근거가 될 수 있을 것으로 기대한다.

체계이론 접근법에서 보는 역량개발은 다양한 요인, 권력의 역학관계 및 유대관계를 포함하는 복 합적인 개입(complex intervention)을 통해 발현되고 발전되어지는 것으로 간주한다. Lusthaus et al. $(1999,2002)$ 이 접근법에 강조하는 중요한 요소 중에 한 가지는 역량개발을 지나치게 도구적으 로 개발하는 대상으로 간주하는 것에 대해 조심해야한다고 한다는 점이다. 자연스럽게 체계이론 접 근법에서는 실제 어떠한 역량개발이던지 현 상황에 대한 엄격한 판단과 조사에 근거하고 다양한 맥 락적 요인(contextual elements)와 연계한 변화에 근거하여 역량이라는 것이 강화되지 않을 수도 있기 때문에 역량강화 사업에 대한 성과를 섣부르게 과장해 해석하는 것을 유의를 해야 한다고 경고 하고 있다.

이와 같은 맥락에서 시스템접근법이 간주하는 역량개발이란 “국가, 지역, 지방자치, 지역조직 및 제도 그리고 국가, 민간 및 공익단체 등을 모두 포함한 거시적인 차원의 전략구성”이여야 그 본래의 의미가 있다고 강조(Morgan, 1996; UNDP, 1999)하고 있으며, 궁극적으로 역량개발이란 "개인, 지 역단체 및 조직으로 구성된 복잡한 네트워크들이 각자의 업무수행 능력을 향상시키는 역동적인 과 정”이며, 이는 “제도적 틀을 통해 체계 내 서로 다른 구성요소들이 어떻게 상호작용 할지 정해지는 복 합적이고 다면적인 것”이라고 정의하고 있다. 이와 같은 관점은 1990 년대 집중적으로 발전된 Sen과 UNDP의 역량중심 접근법(Capability Approach)(UNDP, 1999)에서 많은 영향을 받았고 지난 10여 년간 서구 공여기관과 전문기관에서 부분적으로 도입되어 국제개발 전략 수립과 프로그램의 기획 및 평가 분야에 적지 않은 영향을 미치고 있는 상황이다.

\section{IV. 새로운 역량개발 전략을 위한 시사점}

현재 활용되고 있는 세계은행이나 $\mathrm{OECD}$ 의 역량개발에 대한 실용적인 개념 정리에서 한 발짝 나 아가 제도적 접근법, 조직개발 접근법, 체계이론 접근법 그리고 참여적 접근법의 주요 내용을 살펴보 
고 이와 같은 다양한 접근법이 역량강화를 어떻게 규정하고 있는지 고찰해보았다. 이제 지속가능발전 이라는 커다란 틀에서 역량개발의 개념에 대해 알아보았고 혁신적이고 지속가능한 발전을 이루어내기 위한 수단이자, 지속가능발전의 중요한 목표 그 자체로서 역량개발에 대한 다양한 접근법이 국제사회 에서 정책적으로 중요하게 다뤼지고 있음을 확인하였다. 그러나 동시에 이와 같은 역량개발의 중요성 이 확인되었음에도 불구하고 이제 사업 단위에서 제도, 체계, 사람을 변화하는 역량개발사업과 활동 의 성과를 어떻게 기획하고 이행하며 모니터링하고 평가 할 것이지 쉽지 않은 과제가 산재해있다. 한 국적 상황에서 새로운 사업과 활동을 위한 실천적 시사점을 아래와 같이 제시하고자 한다.

첫째, 중장기적으로 국제개발에서의 역량개발에 대한 근본적인 지식과 이해가 좀 더 깊어져야 한 다. 엄격히 말하자면, 기술 및 지식의 전이가 개인 차원을 넘어서 제도와 사회 차원의 변화를 어떻게 만들어 가는지에 대한 명확한 이론적 답이 하나로 존재하는 것이 아니기 때문이다.

$\mathrm{UN}$ 은 지난 MDGs 세대의 기술 원조가 기술과 지식을 단순히 전달하는 데에 그침으로써 수원국의 사회 경제적 변화를 충분히 이끌어내지 못했다고 평가하며, 수원국의 역량 개발을 위해서는 기술 및 지식의 전이가 개인 차원을 넘어서 제도와 사회 차원의 변화로까지 이어져야 함을 강조하고 있다. 앞 서 역량개발의 다양한 개념과 접근법에서도 소개된 바와 같이, 이와 같은 국제기구와 타 해외공여기관 들의 역량개발 사업에 대한 접근법은 우리 공적개발원조 사업에도 중요한 방향성을 제시하고 있다.

선행연구 ${ }^{10)}$ 에서도 상세히 다맀지만, $\mathrm{KOICA}$ 는 기술협력의 시대적 흐름에 따라 기술전수에 초점을 둔 1 세대와 2 세대 기술협력에서 3 세대 기술협력인 포괄적 역량개발로 나아가기 위해 다양한 노력을 하고 있으나, 다양한 인력 관련 사업은 아직 본격적인 역량개발 패러다임으로의 전환이 이루어졌다고 볼 수는 없다(이태주 외, 2012). 따라서 현재 그리고 가까운 미래의 연수사업 중심의 기술협력에 대한 성과관리를 위해서는 포괄적인 접근을 시도하는 역량개발 성과관리 모형 보다는 교육훈련 성과 관련 에 초점을 두고 발전해나가고 있는 상황이다.

둘째, 공적개발원조에 적용이 가능한 다양한 이론적 · 개념적 접근법을 적용시켜 전체적인 맥락에 서 역량이 어떠한 변화(change)를 이끌어낼 것인가에 집중할 수 있도록 역량개발 사업의 변화이론 (Theory of Change)을 정교화하는데 집중해야 한다.

이와 같은 맥락에서 이와 같은 맥락에서 우리는 지금 현장에서 역량이 어떻게 규정되고 있는지, 어 떠한 접근법과 관점(제도적 접근법, 조직개발접근법, 시스템 접근법, 참여적 접근법 등)에 근거하여 사업에 적용되고 있는지, 향후 어떠한 진입지점(entry points)을 가지고 역량개발 사업과 활동이 기

10) 이태주 · 홍문숙 · 김헌 · 남종민 · 추빛나. 2015. 「연수사업 성과점검 및 성과관리체계 구축연구」. (사)글로벌발전연 구원(ReDI). 성남: 한국국제협력단(발간예정) 
획되어야하는지에 대한 구체적인 논의가 필요한 시점이다. 역량개발 사업의 활동범위, 유형, 목표에 따라 개인(UNICEF, 1998), 조직(Fowler, 1997), 제도(UNDP, 1995) 중에 전략적인 부분을 선택하고 조합할 수 있는 가능성을 실험해보아야한다. 역량강화 사업과 활동 대상 혹은 진입지점(entry point) 을 명료화하는 것은 향후 역량개발사업의 목적과 성과를 면밀히 하고 사업의 활동을 궁극적인 사업성 과와 촘촘히 연계하여 기획하는데 많은 기여를 할 수 있을 것이다.

셋째, 역량개발 사업의 궁극적인 중장기 목표는 수원국의 개발성과에의 기여하는 것임을 좀 더 명 확히 할 필요가 있다. 원조 효과성에 대한 파리 선언 이후 역량개발에 대한 중요성이 국제 사회에서 더욱 부각되면서 개발 목표를 달성하기 위하여 이를 계획, 이행, 관리할 수 있는 수원국의 역량이 필 수적으로 개발되어야 하고, 이러한 역량 개발은 공여국이 단순히 전달해줄 수 있는 것이 아니며 수 원국 내부로부터 이루어져야 한다는 것은 이미 국제적인 조류이다(이태주 외, 2015). 이러한 맥락에 서 우리나라 역량개발사업의 대표주자인 연수사업도 지난 4 5년 간 국제적 논의 추세를 고려하여 많은 변화를 시도한 것으로 나타났다. $\mathrm{KOICA}$ 는 "최근 역량개발을 개인 차원에서 지식의 전수를 넘 어, 조직 및 사회 차원에서 개도국 스스로의 개발 능력을 제고하는 과정(한국국제협력단 역량개발부, 2014)"으로 재정의하였고, 최근 연수사업에 대한 체계적인 성과연구 및 과학적인 지표 도출 작업을 완료했다. 그 결과, KOICA 연수사업의 궁극적인 목적(goal)을 (i) 수원국 제도개선 기여, (ii) 조직역 량강화 기여, (iii) 한-수원국 간 파트너십 강화라는 목표로 좀 더 체계홤하였고 좀 더 명확한 중기성 과들도 발굴하고 있다. 이와 같은 맥락에서 $\mathrm{KOICA}$ 역량개발사업 중 연수사업이 수원국 개발성과 기 여를 강화 방향으로 성과를 체계화하고 만족도 향상을 통해 검증된 단기성과를 넘어 수원국, 수원기 관의 역량강화를 도모하는 개발성과를 부각하고자 하는 것 자체가 중요한 변화라고 할 수 있다. 향후 우리나라 ODA 사업이 연수사업과 마찬가지로 개발성과와의 연계를 좀 더 명확히 하고 중기성과를 도 출할 수 있도록 많은 전략적인 작업들이 진행될 것으로 기대해 본다.

넷째, 프로그램 차원의 역량개발 성과관리 싸이클이 도입되어야 한다. 현재 $\mathrm{KOICA}$ 의 역량개발사 업과 활동은 교육 혹은 보건사업과 같은 섹터 사업 뿐 아니라 전 분야에 걸쳐 진행되고 있다. 그만큼 역량강화 활동이 많이 진행되고 있으며, 또 동시에 이를 위한 성과관리가 복잡할 것이다. 역량개발사 업의 대표 사업인 연수사업에 관한 성과관리 연구 결과 ${ }^{12)}$ 에 의하면 현재 우리나라 해외사업의 경우 기 획 단계부터 프로그램의 차원의 역량개발 성과모델에 근거하여 전체 프로그램의 방향성과 그 세부 목 표와 내용을 구성하지 못한 한계를 발견하였다.

11) 이태주 · 홍문숙 · 김헌 · 남종민 · 추빛나. 2015. 연수사업 성과점검 및 성과관리체계 구축연구」. (사)글로벌발전연 구원(ReDI). 성남: 한국국제협력단(발간예정)

12) 이태주 · 홍문숙 · 김헌 · 남종민 · 추빛나. 2015. 「연수사업 성과점검 및 성과관리체계 구축연구」. (사)글로벌발전연 구원 $(\mathrm{ReDI})$. 성남: 한국국제협력단(발간예정) 


\section{〈그림〉 역량개발 성과관리 사이클}

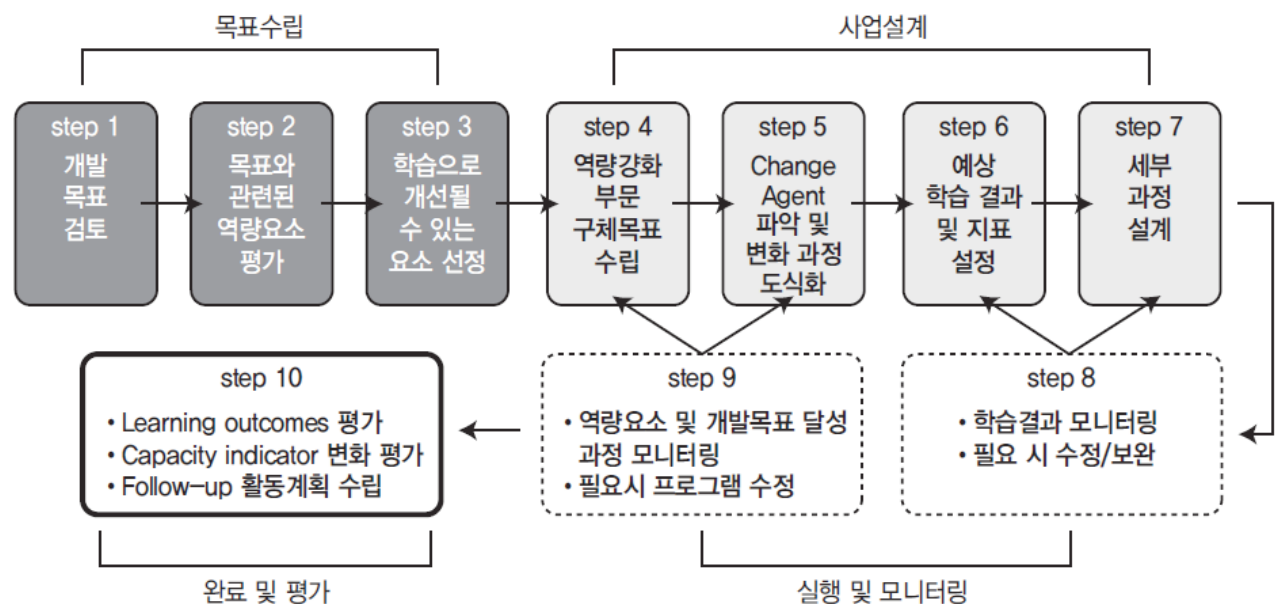

* 출처: 차은주 외, (2014). 재인용함

위의 그림에서 제시한 바와 같이 개발을 위한 역량개발 사업은 이론적으로 4 단계로 관리 및 운영 된다고 요약할 수 있다(WB, 2014). 각 단계별로 상세한 절차를 재구성하여 살펴보면 아래와 같다. ${ }^{13)}$

(i) 1 단계: 역량개발 전체 프로그램이 기여할 개발목표를 분명하게 제시하고 개별사업별로 역량에 대한 내용이 검토되고 확정됨. 이 단계에서 개발목표와 관련된 역량 요소와 측정가능한 지표 를 확인함.

(ii) 2 단계: 제시된 역량개발 성과관리 모형을 참고하여 개별 사업의 기획자는 사업 단위의 변화의 과정을 구체적으로 도식화함. 개별 사업기획자는 역량개발사업 지표 풀을 참고하여 개별사업 의 학습 결과 및 관련 세부 지표를 결정함.

(iii) 3 단계 실행 및 모니터링: 개별 사업 진행자는 사업 실행 과정 중에 학습 결과가 달성되는지, 그리고 역량요소 관련 지표에서 변화를 가져올 가능성이 있는지 지속적으로 모니터링하고 관 련 이해관계자와 그 진행과정을 공유함.

(iv) 4단계 완료 및 평가: 개별 사업 담당자는 계획된 학습 결과의 달성 여부, 목표 역량 요소 변화 및 개발 목표의 달성여부를 원조기관과 공유하고 평가하는 과정을 거침.

13) 이태주 · 홍문숙 · 김헌 · 남종민 · 추빛나. 2015. 「연수사업 성과점검 및 성과관리체계 구축연구」. (사)글로벌발전연 구원 (ReDI). 성남: 한국국제협력단(발간예정) 
위와 같이 좀 더 혁신적인 역량개발 사업들이 단계적으로 관리되고 체계화되기 위해서는 아직은 방법론적으로 많은 한계가 존재한다. 이는 타 해외 원조기관들도 같은 어려움을 겪고 있는 상황이며 국내 개발협력계의 과제만은 아닐 것이다. 반가운 소식은 최근 진행된 세계은행 및 UN의 연구 결과 를 통해 간접적으로나마 역량의 구성요소, 역량의 측정을 위한 방향성에 대한 시사점을 얻을 수 있었 으며, 국내 국제개발협력에 적합한 연구와 평가들이 좀 더 많이 진행되고 있다. 좀 더 혁신적인 정책 수준과 사업 수준의 역량개발 프로그램이 기획되고 이행되기 위해서는 향후 다양한 이론에 근거한 성 과수립, 측정 그리고 보고와 환류를 위한 다양한 도구의 개발에 좀 더 많은 전략적 인풋이 필요할 것 이다.

\section{V. 맺으며}

우리는 아직 개발을 위한 역량개발의 변화이론(theory of change)을 명확히 가지고 있지 않으며 이를 증명하기 위한 방법론적 과제를 지니고 있다. 제도 역량강화를 강조하고 있는 정책 컨설팅 사업 과 사람이 교류하는 것이 핵심 활동인 연수사업과 봉사단의 경우 특히 이와 같은 실천적, 태생적 과제 를 가지고 있는 것이다. 그러나 더이상 역량개발의 효과가 모호하다는 점에 있어 당황할 필요는 없다. 지난 1990년대 역량이라는 개념과 점근법이 개발협력에서 주류 담론으로 안착되던 시기와 달리, 이제 는 국내외적으로 역량개발이 개발협력에서 얼마나 중요한 개념인지, 개발의 성과 달성하기 위해서 역 량이라는 것이 얼마나 중요한 자원인지에 대해서는 어느 정도 합의가 형성되었기 때문이다. 애초부터 역량이라는 것이 단순하고 선형적인 관리를 통해서만 '산출'되는 것이 아니라는 것을 인지하기 시작하 였고 새로 도입되는 SDGs와 관련된 더 임팩트있는 개발성과를 달성하기 위한 수단으로도 역량강화가 그 성과를 모두 측정 할 수 있는지 없는지의 문제를 떠나 이미 중요한 위치를 차지하고 있기 때문이다.

그렇다면 이제 연구자와 개발사업의 기획자와 평가자들은 역량개발을 위한 변화이론의 정립과 방 법론 개발을 위해 무엇을 해야 할까? 역량이라는 창의적이고 유동적인 개념을 다양한 형태와 유형 으로 국제개발협력 사업에 녹여 끓임없이 이론을 검증하고 살아있는 개념(working definition)으로 정교화하는 것을 꾸준히 실천하는 방법 밖에는 대안이 없다. 역량개발이라는 거대한 '모호함' 속에서 사업 각각의 단계마다 의도하지 않은 성공과 예상하지 못한 실패를 만나는 과정, 그 자체가 우리나 라 원조 환경에 적용가능한 역량개발 사업의 변화이론을 하나씩 만들어나는 과정임을 잊지 않았으면 한다. 


\section{〈참고문헌〉}

\section{국내문헌}

김지현. 2015. "Post-2015 개발의제 동향연구 2 : Post-2015 의제에 관한 UN 사무총장 종 합보고서 분석”「개발과 이슈」: 22호 (2015년 1월호). 성남: 한국국제협력단.

박수영, 오수현. 2015. “제3차 개발재원총회와 아디스아바바 행동계획의 함의 분석 연구”.「개

발과 이슈」 24호 (2015년 8월호). (사)글로벌발전연구원 (ReDI). 성남: 한국국제협력단.

이태주, 홍문숙, 강하니, 문기홍, 이경철. Ho Quang Minh, Dao Duy Tung. 2012. 8. 「우

리나라의 기술협력 공적개발원조사업 개선방안」. 글로벌발전연구원(ReDI). 성남:한국국제

협력단. pp.36-54.

이태주, 홍문숙, 김헌, 남종민, 강하니, 이선주, 추빛나, 박희은. 2015. 9. 「연수사업 성과점

검 및 성과관리체계 구축연구」. (사)글로벌발전연구원(ReDI), 성남: 한국국제협력단.

한국국제협력단. 2011. 「국제사회의 역량 개발 지원정책: 기술협력 개혁 논의」. 한국국제협력

단 역량개발부. 성남: 한국국제협력단.

한국국제협력단. 2013.「2013 무상원조사업 수원국 만족도 조사 결과보고서」. 성남: 한국국 제협력단.

홍문숙. 2012. “우리나라 공적개발원조 기술협력 현황과 과제.” 「국제개발협력지」2012년 3

호. 성남: 한국국제협력단.

홍문숙, 유성상, 이태주, 김형식, 오수현. 2013. 타 해외 원조기관 정책 수립 및 사업수행체계 연구, 사회개발팀. 서울: (사)글로벌발전연구원.

\section{국외문헌}

Allen, J. and van der Velden, R. 2005. "The Role of Self-Assessment in Measuring Skills" REFLEX Working paper 2. Research Centre for Education and the Labour Market, Maastricht University (March).

Bell, B. S. \& Federman, J. E. 2010. "Self-assessments of knowledge: Where do we go from here?" [Electronic version]. Cornell University.

Lusthaus, C., Adiren, M., and Perstinger, M. (1999), 'Capacity Development: Definitions, Issues and Implications for Planning, Monitoring and Evaluation', Universalia Occasional Paper, No. 35. September 1999. 
OECD. 2006. The Challenge of Capacity Development: Working Towards Good

Practice Paris: Organisation for Economic Co-operation and Development (OECD). OECD/DAC. 2011. "Perspective Note: Technical Co-operation for Capacity Development." Pearson (2011), 'Training and Beyond: Seeking Better Practices for Capacity Development', OECD Development Cooperation Working Papers, No. 1, Paris: OECD.

Otoo, S., Agapitova, N., \& Behrens, J. 2009. “The Capacity Development Results Framework: A Strategic and Results-oriented Approach to Learning for Capacity Development." World Bank Institute.

World Bank. 2009. The Capacity Development Results Framework: A strategic and results-oriented approach to learning for capacity development. Washington D. C.: World Bank.

World Bank. 2012. Strengthening Inclusive Ownership Through Capacity Development: Operational Lessons from Case Studies. Washington D.C.: World Bank. 